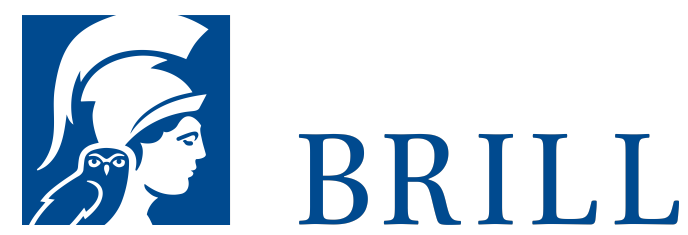

\title{
Summa und System
}

Historie und Systematik vollendeter bottom-up- und top-downTheorien

Author: Jens Lemanski

$>$ Bottom-up $<$ und >top-down $<$ sind heutzutage gängige Methodenbezeichnungen in allen Bereichen der Wissenschaft. Dennoch sind beide Methoden keine Entdeckung der Moderne, sondern wurden unter Begriffen wie beispielsweise $>$ Auf- $<$ und $>$ Abstieg $<$, >Induktion< und >Deduktion $<$ in der Wissenschaftsgeschichte häufig verwendet, um komplexe Wissensbestände vollständig aufzuarbeiten und zu strukturieren. Paradigmatisch für eine derartige Aufarbeitung stehen die mittelalterliche Summa und das neuzeitliche System. Aktuellen Studien zufolge hat aber bereits Dionysius Areopagita in der Spätantike eine derartige Summe verfasst, während in der Neuzeit erst J. G. Fichtes Wissenschaftslehre (1804) allen Systemansprüchen genügen konnte. Daher beschäftigt sich die vorliegende Studie mit den Auf- und Abstiegsmethoden bei Dionysius und Fichte, ihrer antiken Vorgeschichte und kontrastiert ihre Methoden mit der aktuellen Wissenschaftsphilosophie. Dabei zeigt sich, dass beide Autoren bei der Aufstiegs- bzw. bottom-up-Methode bislang unberücksichtigte Strategien zur Lösung des Induktionsproblems anwenden.

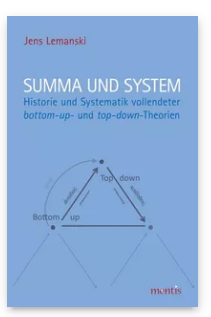

Pages: 306 Seiten Language: German

Subjects:

General, Philosophy

Publisher: Brill | mentis

E-Book (PDF)

Released online: 04 Apr 2013

ISBN: 978-3-

89785-965-4

List price

Paperback

Publication date: 04 Apr 2013 ISBN: $978-3^{-}$ 89785-801-5 List price 
For more information see brill.com

Order information: Order online at brill.com +44330 333 0049 | customerservices@brill.com Submission information: brill.com/authors

Titles published by Brill | Fink, Brill | mentis or Brill | Schöningh: +49(o)715413279216| brill@brocom.de 